\title{
Utilization Trends and Concentration Ratio of Korean Medicine: Based on the National Health Insurance Data
}

\author{
Hye-Jae Lee ${ }^{1}$, Hye In Jeong ${ }^{2}$, Kyeong Han Kim ${ }^{3,4}$ * \\ ${ }^{1}$ Department of Pharmacy, College of Pharmacy, Woosuk University, Wanju, Republic of Korea \\ ${ }^{2}$ Department of Preventive Medicine, College of Korean Medicine, Kyung Hee University, Seoul, Republic of Korea \\ ${ }^{3}$ Woosuk Institute of Smart Convergence Life Care (WSCLC), Woosuk University, Wanju, Republic of Korea \\ ${ }^{4}$ Department of Preventive Medicine, College of Korean Medicine, Woosuk University, Wanju, Republic of Korea
}

Received July 20, 2021

Reviewed July 22, 2021

Accepted August 23, 2021

\section{*Corresponding Author}

Kyeong Han Kim

Department of Preventive Medicine,

College of Korean Medicine, Woosuk

University, 443, Samnye-ro, Samnye-eup,

Wanju 55338, Republic of Korea

Tel: +82-63-290-9031

E-mail: solip922@hanmail.net
Objectives: Although Korean Medicine (KM) subsidized by the National Health Insurance $(\mathrm{NHI})$ has been used for a long time, there has been no active analysis using claims data . Therefore, the purpose of this study was to examine the NHI KM utilization trend using NHI statistics and to measure the level of market concentration by year.

Methods: By restructuring the contents of NHI Statistics for Pharmaceuticals for 20102019, the claim cases, costs, and annual growth rates of KM were demonstrated by year, sex, age group, region, therapeutic group, and KM treatment. The proportion of highly used $k$ treatments in cost was calculated as the concentration ratio (CR) $k$ and its trend by year was investigated.

Results: In 2019, the NHI cost on KM amounted to $\$ 38.2$ billion KRW, increasing by $11.6 \%$ per year on average in 2010-2019. Notably, KM was used more frequently among women and patients aged $\geq 65$ years, and the mixed formulation accounted for $95 \%$ of the total cost of KM. The CR of the simple formulation increased rapidly, whereas that of the mixed formulation remained constant. In 2019, three simple formulation treatmentspeony, licorice, and ginseng- accounted for $93.8 \%$ of the total cost for KM (CR3 = 93.8\%). Conclusion: $\mathrm{NHI}$ KM is rapidly increasing. Investigating the $\mathrm{CR}$ of $\mathrm{KM}$ confirmed that KM prescriptions have been concentrated in small numbers over the past 10 years.

Keywords: korean medicine, herbal preparation, national health insurance, concentration ratio, utilization trend

\section{INTRODUCTION}

Herbal preparations are defined as "dried, cut, or refined herbal substances, mainly collected from animals, plants, or minerals" under the Pharmaceutical Law, wherein certain herbal preparations are covered by health insurance services [1]. As of 2020 , there were 1,327 herbal preparations in total available on the health insurance service, comprising 682 single herbal preparations, 645 mixed herbal preparations, and 56 standard prescriptions [2].

Recently, Korean medical care has become health insuranceoriented and the overall market for its health insurance has also been steadily increasing. However, there has been no change in the type of medicine that can be covered by health insurance services, and thus the usage of herbal preparations is low, accounting for a low percentage of total medical expenses. Currently, 56 herbal preparations are covered by health insurance, which have been maintained since 1990 following its expansion from 36 in 1988 due to the recognition of 26 mixed prescriptions in 1987 [3].

Herbal preparations are relatively safe since they are based on traditionally used prescriptions; however, they can cause synergies or drug interactions when administered in combination with other medications. Studies that show this have included interactions with certain drugs or diseases such as antiplatelet drugs and osteoarthritis, reporting that a combination 
of herbal preparations and medicines is relatively safe $[4,5]$.

Previous studies have also shown that drug costs in standard prescriptions were concentrated on a small number of drugs, with 10 herbal preparations accounting for more than half of the claims and the top 20 diseases accounting for $90 \%$ of the total claims [6]. Although there have been suggestions-such as adding new prescriptions or improving manufacturing methods-instead of deleting those with low frequency of use, many prescriptions remain concentrated on this small number of drugs [7].

Despite this situation, the current use of herbal preparations using health insurance claims data remains unreported. With the government's policy to strengthen guarantees, Korean medicine (KM) is also being promoted, and it is therefore necessary to investigate the changes in how herbal preparations are used. To that end, there have been studies that have analyzed major diseases and standard prescriptions using health insurance data [6], studies on doctors' drug administration [8], and studies that investigated doctors' recognition and satisfaction [9].

In this study, we examined how the status of herbal preparations has changed over the past decade. Since prior research has reported the concentration of their use in a small number of herbal preparations, the study is intended to analyze the use of herbal preparations and interpret their policy implications by applying the concept of market concentration to quantitatively represent them. The results of this study will provide basic data on the research and policies related to herbal preparations by suggesting how they should be used nationwide.

\section{MATERIALS AND METHODS}

\section{Source of data}

This study used data from one of the statistics using health insurance claims, referred to as "medicine statistics covered by insurance." [10] The contents of the herbal preparations in this study were extracted and reconstructed from the Health Insurance Review and Assessment Service (hereinafter referred to as HIRA), which publishes medicine statistics every year. The herbal preparations presented in this study were based on single herbal and mixed herbal preparations listed in the "A health insurance list of herbal preparations and upper limit amount," which included health insurance claims other than medical benefits. The analysis period starts in 2010, when herbal medicine statistics started being produced, and continues until the most recent data, 2019.

\section{Variables}

The status of herbal preparation use was presented as the number of claims, the expense of claims, and the rate of their increase. Specifically, the number of claims for each year refers to the number of medical statements prescribed by herbal preparations, whereas the expense claimed is the sum of insurance benefit costs and the patients' own charges multiplied by the unit price and the cost of use for each herbal preparation. To quantify the change in claims for 2010-2019, the growth rate period was calculated as the compound annual growth rate (CAGR), which can be interpreted as the average annual growth rate of the value $(\mathrm{V})$ over a period of time ( $\mathrm{t}$ years).

$\mathrm{CAGR}=(\mathrm{V}$ final $/ \mathrm{V}$ begin $) \wedge(1 / \mathrm{t})-1$

\section{Method of analysis}

The study analysis was divided into three parts: (1) macrolevel analysis of the trend in Korean herbal preparation use, (2) analysis of the status of use for individual herbal preparations, and (3) market concentration of herbal preparations. First, to analyze the trend of herbal preparation use in Korea, both the total number and cost of claims were presented on an annual basis and the increase rate was calculated and compared to the total KM treatment expenses from health insurance. Afterward, this was again classified by sex (male and female) and by patient age (0-19 years, 20-64 years, and $\geq 65$ years). Moreover, the use of herbal preparations was presented in subdivisions by region and by group of medicinal efficacies, confirming which region and which group of drugs with a certain medical efficacy were used more frequently and had increased rapidly. For the efficacy group based on the Ministry of Food and Drug Safety, only statistics for 2010-2017 were presented, which was the only period for which data could be obtained. Second, an analysis of individual herbal preparation claims identified which of the single or mixed herbal preparations were used the most and had increased in use. Finally, the market concentration of frequently used herbal preparations was presented as a concentration, which quantitatively identified its changes during the analysis period. Market concentration is a concept that measures the monopoly power and level of market competition of certain products in the market. However, in this study, the concentration ratio $\mathrm{k}(\mathrm{CRk})$ was used to refer to prior research 
Hye-Jae Lee, et al.

to indicate the share of the top $\mathrm{k}$ products in the market [11]. In other words, CR3 refers to the share of the top three products in the overall market, wherein a high concentration meant that only a few products were mainly used. In this study, CR3, CR5, and CR10 were measured for single herbal preparations and CR3, CR5, CR10, and CR20 were measured for mixed herbal preparations.

\section{RESULTS}

\section{Annual claim status of herbal preparations}

According to the 2010-2019 health insurance statistics, the number of herbal preparations claims and expenses steadily increased (Table 1). Specifically, the expenses of claims for herbal preparations increased by $11.6 \%$ annually while the number of claims increased by $22.5 \%$ annually, which indicates that the expenses of claims per case have been decreasing. In fact, the expense in 2010 was noted to be $\$ 36,000 \mathrm{KRW}$ per prescription of herbal preparations, which decreased to $15,000 \mathrm{KRW}$ per prescription in 2019. Moreover, according to a survey of claims for herbal preparations by type of nursing institution, herbal preparations were only used in KM hospitals and medicine clinics; by 2019, these institutions charged 2.7 billion KRW and 35.6 billion KRW, respectively. Furthermore, the rate of increase in prescribing expenses of KM clinics was $12.0 \%$, which was higher than that of KM hospitals (6.7\%). Therefore, herbal preparations were found to be mainly used in KM clinics rather than hospitals.

However, calculating the prescription expense per case showed that KM hospitals spent approximately 10,000 KRW in 2019 on average, whereas KM clinics only spent approximately $1,450 \mathrm{KRW}$ on average, indicating that KM clinics prescribed relatively cheaper preparations. According to sexspecific usage, as of 2019, the number of claims made by men and women were 8.26 million and 16.49 million, respectively, costing 12.9 billion KRW and 25.4 billion KRW, respectively. Over the past decade, the use of herbal preparations by women was noted to have increased more rapidly than that by men, with women's claims increasing by $12.3 \%$ annually and men's claims by $10.3 \%$ annually. According to age-specific usage, 450,000 cases, 3.18 million cases, and 20.11 million cases of herbal preparations were reported in the age groups 0-19 years, 20-64 years, and $\geq 65$ years, respectively. Over the past decade, the use of herbal preparations has decreased in the $0-19$ years

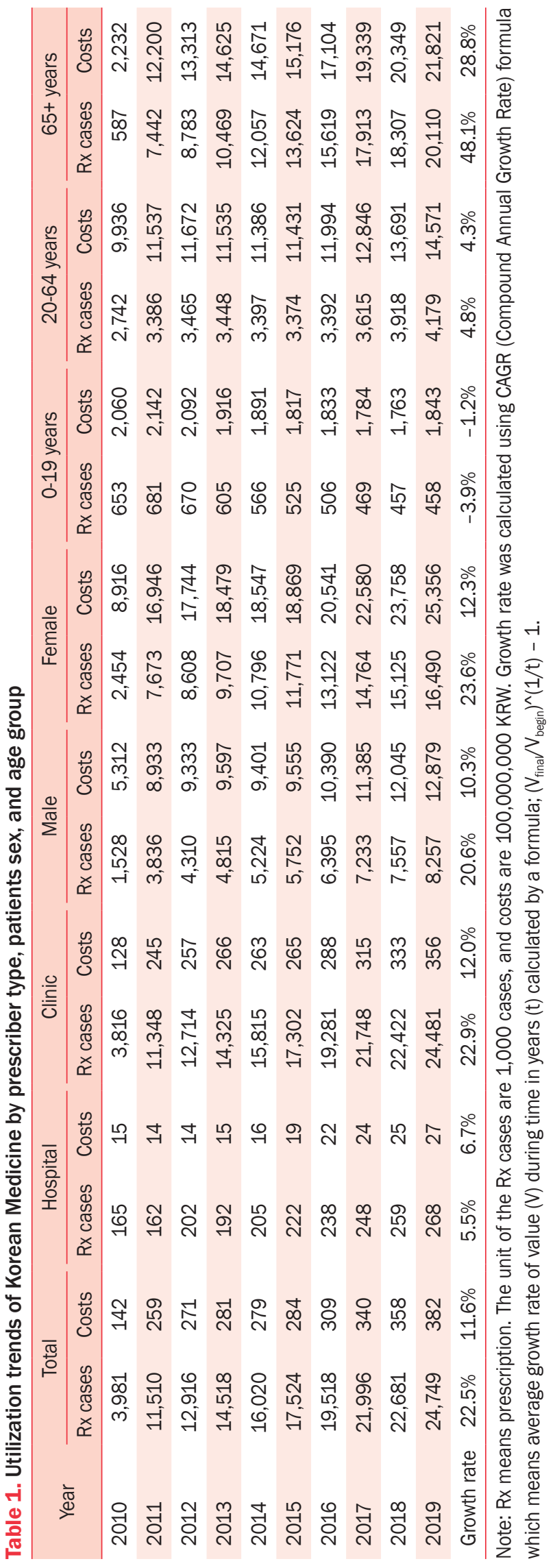


group but has slightly increased in the 20-64 years group. However, use in the 20-64 years old group was lower than the overall average growth rate, which increased by $48.1 \%$ per year in the $\geq 65$ years group, indicating that the use of herbal preparations among the elderly has led to an increase in the number of herbal preparations claims (Table 1 and Fig. 1). Claims by age group were also high among those aged $\geq 65$ years, but the average annual growth rate was $28.8 \%$, which was lower than that of the number of claims.

Looking at the expenses of claims made by 17 cities and provinces between 2010 and 2019, Seoul was found to use herbal preparations the most, followed by Gyeonggi, Busan,
Gyeongbuk, and Gyeongnam (Table 2). As of 2019, Seoul had used 8.1 billion KRW worth of herbal preparations, while Gyeonggi had used $\# 7.7$ billion KRW worth of herbal preparations. During the analysis period, Sejong's growth rate reached $27.5 \%$, whereas the country's growth rate reached $11.6 \%$. Since then, Gyeongnam, Busan, Gyeongbuk, and Jeju have been identified as areas with high growth rates.

As a result of classifying herbal preparations into therapeutic groups between 2010 and 2019, the use of drugs for the nervous system and sensory organs (190) was found to be the most common, followed by use as digestive organ solvents (239), heat-resisting painkillers (114), and digestive medicines (233)
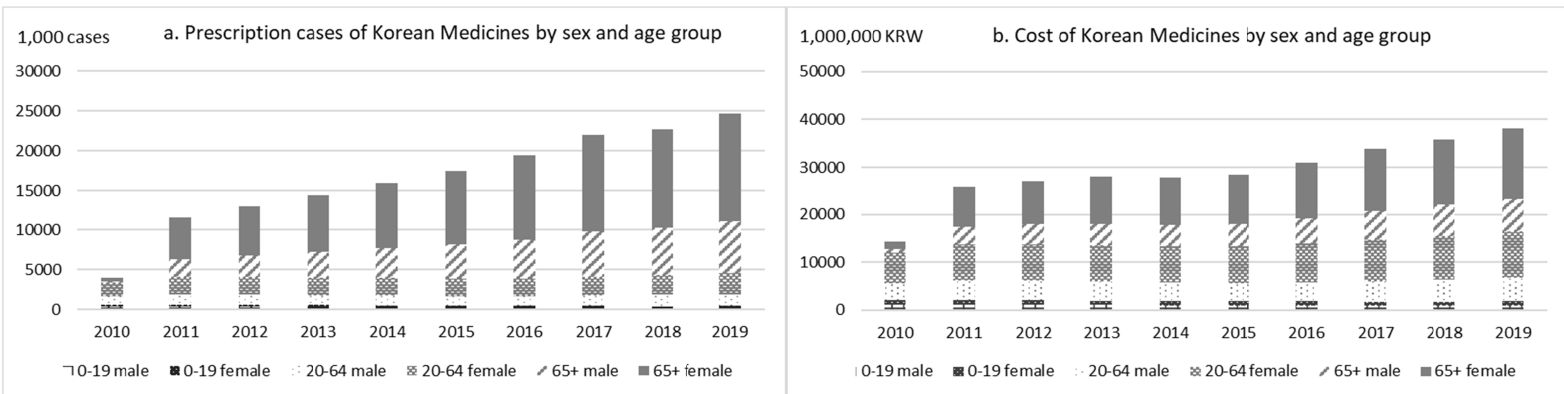

Figure 1. Utilization trends of Korean Medicines by sex and age group: prescription cases (A) and cost (B).

Table 2. Utilization trends of Korean Medicines by region (unit: 1,000,000 KRW)

\begin{tabular}{|c|c|c|c|c|c|c|c|c|c|c|c|}
\hline Region & 2010 & 2011 & 2012 & 2013 & 2014 & 2015 & 2016 & 2017 & 2018 & 2019 & Growth rate \\
\hline Total & 14,226 & 25,880 & 27,078 & 28,076 & 27,950 & 28,428 & 30,932 & 33,968 & 35,803 & 38,237 & $11.6 \%$ \\
\hline Seoul & 3,472 & 5,390 & 5,537 & 5,584 & 5,666 & 5,914 & 6,612 & 7,152 & 7,632 & 8,109 & $9.9 \%$ \\
\hline Busan & 802 & 1,644 & 1,808 & 1,920 & 1,824 & 1,827 & 2,082 & 2,269 & 2,419 & 2,646 & $14.2 \%$ \\
\hline Gyeongnam & 603 & 1,266 & 1,452 & 1,610 & 1,606 & 1,682 & 1,753 & 1,914 & 1,954 & 2,109 & $14.9 \%$ \\
\hline Incheon & 689 & 1,175 & 1,193 & 1,260 & 1,266 & 1,247 & 1,365 & 1,497 & 1,698 & 1,834 & $11.5 \%$ \\
\hline Daegu & 640 & 1,153 & 1,250 & 1,293 & 1,325 & 1,359 & 1,457 & 1,596 & 1,672 & 1,784 & $12.1 \%$ \\
\hline Daejeon & 919 & 1,482 & 1,448 & 1,509 & 1,440 & 1,376 & 1,481 & 1,575 & 1,628 & 1,718 & $7.2 \%$ \\
\hline Gwangju & 568 & 867 & 955 & 1,077 & 1,178 & 1,215 & 1,306 & 1,541 & 1,559 & 1,640 & $12.5 \%$ \\
\hline Chungbuk & 533 & 974 & 1,000 & 1,015 & 928 & 939 & 1,004 & 1,096 & 1,134 & 1,235 & $9.8 \%$ \\
\hline Gangwon & 439 & 915 & 984 & 1,024 & 960 & 948 & 1,008 & 1,082 & 1,138 & 1,172 & $11.5 \%$ \\
\hline Ulsan & 414 & 610 & 611 & 604 & 551 & 550 & 594 & 682 & 775 & 857 & $8.4 \%$ \\
\hline Јeju & 131 & 353 & 371 & 365 & 335 & 330 & 372 & 413 & 501 & 543 & $17.1 \%$ \\
\hline Sejong & - & - & 33 & 85 & 86 & 87 & 100 & 117 & 155 & 181 & $27.5 \%$ \\
\hline
\end{tabular}


Hye-Jae Lee, et al.

Table 3. Utilization trends of Korean Medicines by treatment group (unit: 1,000,000 KRW)

\begin{tabular}{|c|c|c|c|c|c|c|c|c|c|}
\hline Treatment groups ${ }^{1)}$ & 2010 & 2011 & 2012 & 2013 & 2014 & 2015 & 2016 & 2017 & Growth rate \\
\hline Total & 14,114 & 25,524 & 26,548 & 27,249 & 26,946 & 27,276 & 29,425 & 32,179 & $12.5 \%$ \\
\hline $\begin{array}{l}\text { (190) Other medicines for nervous } \\
\text { system and sensory organs }\end{array}$ & 4,006 & 8,577 & 8,262 & 8,166 & 7,503 & 7,426 & 7,880 & 8,445 & $11.2 \%$ \\
\hline (239) Other digestive drugs & 1,854 & 3,114 & 3,511 & 3,965 & 4,638 & 5,642 & 6,439 & 7,481 & $22.1 \%$ \\
\hline $\begin{array}{l}\text { (114) Antipyretic, analgesic, anti- } \\
\text { inflammatory }\end{array}$ & 3,923 & 5,932 & 6,196 & 6,029 & 5,517 & 5,238 & 5,453 & 5,614 & $5.3 \%$ \\
\hline $\begin{array}{l}\text { (222) Jinhae Geodamje (cough } \\
\text { suppressant, sputum remover) }\end{array}$ & 1,065 & 1,432 & 1,526 & 1,519 & 1,676 & 1,687 & 1,781 & 1,857 & $8.3 \%$ \\
\hline (235) Antiemetics & 154 & 728 & 954 & 1,215 & 1,369 & 1,184 & 1,300 & 1,654 & $40.4 \%$ \\
\hline (329) Other nourishing agents & 560 & 1,556 & 1,599 & 1,681 & 1,587 & 1,542 & 1,649 & 1,649 & $16.7 \%$ \\
\hline $\begin{array}{l}\text { (119) Other drugs for central nervous } \\
\text { system }\end{array}$ & 93 & 145 & 159 & 174 & 207 & 205 & 261 & 392 & $22.8 \%$ \\
\hline $\begin{array}{l}\text { (399) Metabolic drugs, not elsewhere } \\
\text { classified }\end{array}$ & 29 & 156 & 168 & 191 & 170 & 166 & 169 & 177 & $29.5 \%$ \\
\hline (229) Other respiratory drugs & 71 & 90 & 108 & 115 & 109 & 96 & 108 & 112 & $6.7 \%$ \\
\hline (219) Other circulatory drugs & 22 & 52 & 73 & 70 & 70 & 72 & 83 & 95 & $23.2 \%$ \\
\hline (238) Laxative & 18 & 35 & 45 & 46 & 50 & 51 & 49 & 51 & $16.0 \%$ \\
\hline (231) Dental oral medicine & 18 & 29 & 35 & 40 & 33 & 29 & 33 & 37 & $10.8 \%$ \\
\hline $\begin{array}{l}\text { (259) Other drugs for genitourinary } \\
\text { organs and anal use }\end{array}$ & 15 & 19 & 21 & 24 & 23 & 22 & 26 & 32 & $11.4 \%$ \\
\hline
\end{tabular}

Note: Treatments groups are defined by Korean Ministry of Food and Drug Safety (MFDS). Statistics of classification by MFDS treatment group were available until 2017.

(Table 3). Other groups of drugs with a rapid increase in prescription expenses were as follows: emetic drugs (235) were the highest, with a $40.4 \%$ increase annually; followed by metabolic drugs (399), which were not classified separately and increased by $29.5 \%$ annually; and lastly by other metabolic drugs (219), which increased by $23.2 \%$ annually and were higher than the herbal preparations overall growth rate of $12.5 \%$.

\section{Herbal preparations claims per case}

Looking at the claims for single herbal preparations for 2010-2019, these preparations were found to have the highest levels of Paeonia lactiflora and Glycyrrhizae Radix, for which the annual usage increased rapidly (Table 4, Fig. 2A). In 2019, the claims for Paeonia lactiflora were about 11.1 billion KRW, and those for Glycyrrhizae Radix were about $\$ 600$ million KRW, with an annual average growth rate of $14.0 \%$ and $40.4 \%$, respectively. Subsequently, there were many claims, such as Glycyrrhizae Radix, Panax ginseng, Angelica koreana, and Aralia cordata. In the case of single herbal preparations, the expenses of claims for many drugs decreased during the analysis period, while the concentration of claims on the top drugs intensified. On the other hand, examining the claims of mixed herbal preparations during the same period showed that Ojeok-san was used the most annually, with a claim amounting to 7.9 billion KRW in 2019. Furthermore, the fastest-growing herbal preparation was Gungha-tang, which increased by $80 \%$ annually, followed by Gumi-Ganghwaltang, Banha-Sashimtang, 
Table 4. Utilization trends of highly used Korean Medicines: simple formulation (unit: 1,000,000 KRW)

\begin{tabular}{|c|c|c|c|c|c|c|c|c|c|c|c|}
\hline Treatments & 2010 & 2011 & 2012 & 2013 & 2014 & 2015 & 2016 & 2017 & 2018 & 2019 & CAGR \\
\hline Total (simple formulation) & 111 & 355 & 529 & 826 & 1,003 & 1,152 & 1,506 & 1,788 & 1,825 & 1,951 & $37.5 \%$ \\
\hline Paeoniae Radix & 9 & 67 & 141 & 276 & 375 & 496 & 711 & 928 & 1,008 & 1,113 & $95.1 \%$ \\
\hline Glycyrrhizae Radix & 7 & 43 & 90 & 187 & 252 & 327 & 450 & 556 & 605 & 657 & $14.0 \%$ \\
\hline Ginseng Radix & 3 & 6 & 3 & 4 & 43 & 112 & 121 & 90 & 67 & 61 & $40.4 \%$ \\
\hline Angelicae Pubescentis Radix & 1 & 7 & 13 & 17 & 22 & 20 & 26 & 27 & 19 & 20 & $24.8 \%$ \\
\hline Osterici Radix & 3 & 12 & 16 & 26 & 45 & 38 & 40 & 37 & 23 & 18 & $22.2 \%$ \\
\hline Saposhnikoviae Radix & 2 & 10 & 15 & 18 & 28 & 26 & 29 & 29 & 19 & 17 & $12.1 \%$ \\
\hline Angelicae gigantis Radix & 5 & 20 & 31 & 39 & 36 & 24 & 24 & 23 & 16 & 15 & $24.9 \%$ \\
\hline Cinnamomi Ramulus & 3 & 10 & 20 & 27 & 17 & 12 & 19 & 23 & 17 & 13 & $17.0 \%$ \\
\hline Zingiberis Rhizoma Recens & 2 & 3 & 7 & 6 & 5 & 8 & 15 & 18 & 15 & 12 & $7.4 \%$ \\
\hline Atractylodis Rhizoma & 3 & 9 & 14 & 17 & 21 & 16 & 19 & 18 & 12 & 11 & $25.7 \%$ \\
\hline Zizyphi Fructus & 2 & 4 & 8 & 10 & 7 & 4 & 6 & 7 & 7 & 7 & $2.4 \%$ \\
\hline Rehmanniae Radix Preparat & 2 & 8 & 9 & 10 & 7 & 3 & 3 & 4 & 3 & 1 & $13.2 \%$ \\
\hline Schizonepetae Spica & 1 & 1 & 1 & 1 & 1 & 0 & 0 & 1 & 0 & 1 & $12.5 \%$ \\
\hline Liriopes Radix & 2 & 7 & 4 & 7 & 13 & 11 & 17 & 14 & 8 & 1 & $36.0 \%$ \\
\hline Poria & 9 & 13 & 14 & 16 & 9 & 3 & 2 & 1 & 1 & 1 & $10.7 \%$ \\
\hline Rehmanniae Radix & 2 & 3 & 2 & 1 & 1 & 1 & 0 & 1 & 0 & 0 & $19.1 \%$ \\
\hline Peucedani Radix & 0 & 0 & 0 & 0 & 1 & 0 & 0 & 1 & 0 & 0 & $12.0 \%$ \\
\hline Puerariae Radix & 3 & 13 & 15 & 16 & 14 & 5 & 3 & 1 & 1 & 0 & $25.4 \%$ \\
\hline Pinelliae Rhizoma & 4 & 12 & 14 & 13 & 17 & 16 & 7 & 1 & 1 & 0 & $29.5 \%$ \\
\hline Scutellariae Radix & 2 & 3 & 3 & 3 & 1 & 0 & 0 & 0 & 0 & 0 & $1.8 \%$ \\
\hline
\end{tabular}

Note: Treatments are ordered by cost in 2019. CAGR (Compound Annual Growth Rate) is average growth rate of value (V) during time in years (t) calculated by a formula; $\left(\mathrm{V}_{\text {final }} / \mathrm{V}_{\text {begin }}\right)^{\wedge}(1 / \mathrm{t})-1$.
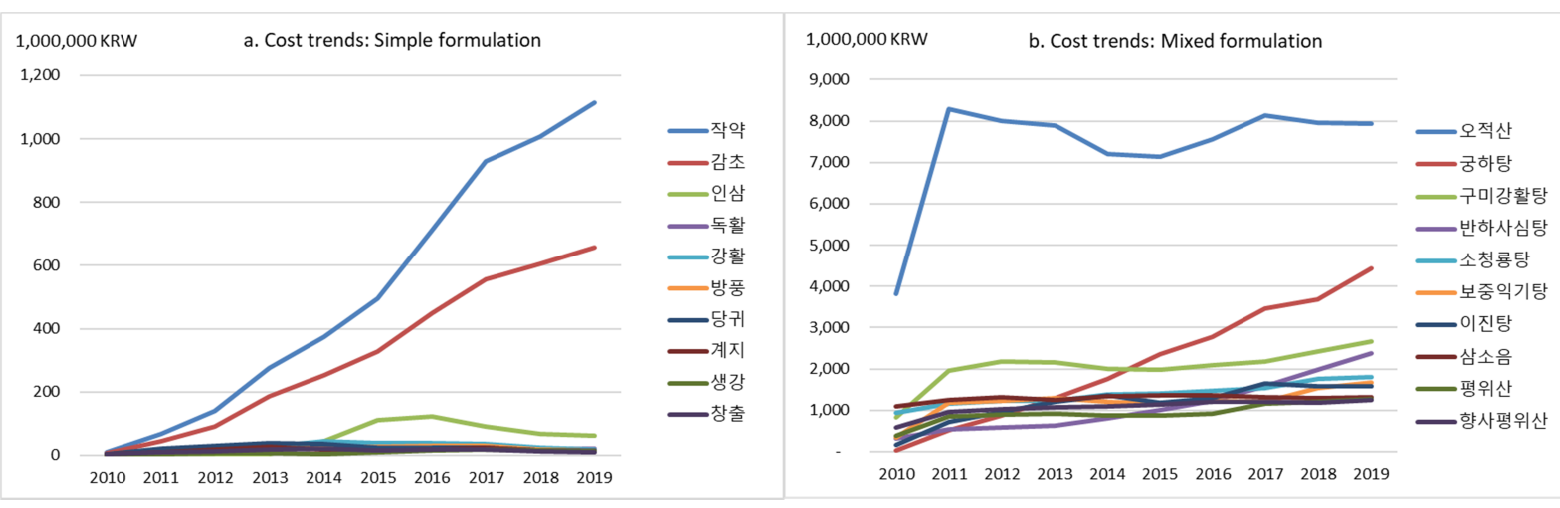

Figure 2. Utilization trends of Korean Medicines by formulation: simple formulation (A) and mixed formulation (B).

Socheongryong-tang, and Bojungikgi-tang (Table 5, Fig. 2B). The growth rates of Leejin-tang, Hwangryeon-Haedogtang, and Banha-Sashimtang were also noted to be high.

\section{Concentration of claims for high-use herbal preparations}

The concentrations of claims for 2010-2019 are presented separately for single and mixed herbal preparations (Table 6). Based on the insurance payment list of herbal preparations in December 2019, single-extract preparations had a total of 67 
Hye-Jae Lee, et al.

Table 5. Utilization trends of highly used Korean Medicines: mixed formulation (unit: 1,000,000 KRW)

\begin{tabular}{|c|c|c|c|c|c|c|c|c|c|c|c|}
\hline Treatments & 2010 & 2011 & 2012 & 2013 & 2014 & 2015 & 2016 & 2017 & 2018 & 2019 & CAGR \\
\hline Total (mixed formulation) & 14,114 & 25,523 & 26,548 & 27,249 & 26,946 & 27,275 & 29,425 & 32,179 & 33,977 & 36,285 & $11.1 \%$ \\
\hline Ojeok-san & 3,809 & 8,292 & 7,992 & 7,883 & 7,207 & 7,126 & 7,563 & 8,123 & 7,947 & 7,932 & $8.5 \%$ \\
\hline Gungha-tang & 22 & 522 & 865 & 1,302 & 1,754 & 2,365 & 2,776 & 3,456 & 3,676 & 4,435 & $80.3 \%$ \\
\hline Gumiganghwal-tang & 833 & 1,956 & 2,179 & 2,162 & 2,010 & 1,972 & 2,088 & 2,187 & 2,417 & 2,661 & $13.8 \%$ \\
\hline Banhasasim-tang & 312 & 534 & 595 & 627 & 809 & 996 & 1,234 & 1,575 & 1,981 & 2,388 & $25.4 \%$ \\
\hline Socheongryong-tang & 949 & 1,162 & 1,236 & 1,228 & 1,373 & 1,406 & 1,476 & 1,537 & 1,757 & 1,808 & $7.4 \%$ \\
\hline Bojungikgi-tang & 349 & 1,175 & 1,217 & 1,298 & 1,210 & 1,165 & 1,234 & 1,215 & 1,533 & 1,675 & $19.0 \%$ \\
\hline Yijin-tang & 154 & 728 & 954 & 1,215 & 1,369 & 1,184 & 1,301 & 1,654 & 1,590 & 1,588 & $29.6 \%$ \\
\hline Samsoeum & 1,086 & 1,256 & 1,304 & 1,246 & 1,346 & 1,352 & 1,355 & 1,310 & 1,296 & 1,320 & $2.2 \%$ \\
\hline Pyungwi-san & 380 & 855 & 892 & 921 & 865 & 861 & 920 & 1,170 & 1,212 & 1,277 & $14.4 \%$ \\
\hline Hyangsapyeongwi-san & 594 & 964 & 1,025 & 1,077 & 1,084 & 1,129 & 1,198 & 1,208 & 1,176 & 1,247 & $8.6 \%$ \\
\hline Youngyopaedoc-san & 515 & 719 & 815 & 846 & 866 & 782 & 830 & 880 & 956 & 1,043 & $8.2 \%$ \\
\hline $\begin{array}{l}\text { Banhabaekchulchoenma- } \\
\text { tang }\end{array}$ & 494 & 674 & 657 & 639 & 690 & 834 & 908 & 872 & 965 & 932 & $7.3 \%$ \\
\hline Hyunggaeyungyo-tang & 282 & 351 & 400 & 423 & 506 & 536 & 570 & 619 & 738 & 835 & $12.8 \%$ \\
\hline Galgeun-tang & 973 & 1,312 & 1,291 & 1,242 & 771 & 549 & 612 & 704 & 726 & 801 & $-2.1 \%$ \\
\hline Kamisoyo-san & 453 & 683 & 656 & 640 & 570 & 517 & 567 & 607 & 645 & 707 & $5.1 \%$ \\
\hline Soshiho-tang & 319 & 427 & 411 & 401 & 470 & 476 & 501 & 551 & 576 & 654 & $8.3 \%$ \\
\hline Hwangryunhaedok-tang & 72 & 112 & 127 & 152 & 188 & 193 & 251 & 382 & 513 & 594 & $26.4 \%$ \\
\hline Insampaedok-san & 651 & 730 & 730 & 693 & 712 & 688 & 656 & 628 & 617 & 584 & $-1.2 \%$ \\
\hline Pamul-tang & 194 & 324 & 319 & 308 & 294 & 306 & 348 & 376 & 401 & 471 & $10.4 \%$ \\
\hline Bulhwangeumjeonggi-san & 135 & 231 & 267 & 283 & 264 & 270 & 311 & 318 & 358 & 408 & $13.0 \%$ \\
\hline
\end{tabular}

Note: Treatments are ordered by cost in 2019. CAGR (Compound Annual Growth Rate) is average growth rate of value (V) during time in years (t) calculated by a formula; $\left(\mathrm{V}_{\text {final }} / \mathrm{V}_{\text {begin }}\right)^{\wedge}(1 / \mathrm{t})-1$.

Table 6. Concentration ratio (CR) trends of highly used Korean Medicines

\begin{tabular}{|c|c|c|c|c|c|c|c|c|c|c|}
\hline Concentration ratio & 2010 & 2011 & 2012 & 2013 & 2014 & 2015 & 2016 & 2017 & 2018 & 2019 \\
\hline \multicolumn{11}{|l|}{ Simple formulation } \\
\hline $\begin{array}{l}\text { Total cost of the market } \\
(1,000,000 \mathrm{KRW})\end{array}$ & 111 & 356 & 530 & 826 & 1,004 & 1,152 & 1,506 & 1,789 & 1,826 & 1,951 \\
\hline $\mathrm{CR}_{3}$ & $22.1 \%$ & $36.5 \%$ & $49.4 \%$ & $60.7 \%$ & $66.9 \%$ & $81.2 \%$ & $85.1 \%$ & $88.0 \%$ & $92.1 \%$ & $93.8 \%$ \\
\hline $\mathrm{CR}_{5}$ & $29.7 \%$ & $44.0 \%$ & $56.3 \%$ & $67.1 \%$ & $74.8 \%$ & $86.8 \%$ & $89.7 \%$ & $91.7 \%$ & $94.3 \%$ & $95.8 \%$ \\
\hline $\mathrm{CR}_{10}$ & $44.4 \%$ & $59.4 \%$ & $69.6 \%$ & $77.4 \%$ & $85.2 \%$ & $94.5 \%$ & $96.7 \%$ & $97.8 \%$ & $98.6 \%$ & $99.2 \%$ \\
\hline \multicolumn{11}{|l|}{ Mixed formulation } \\
\hline $\begin{array}{l}\text { Total cost of the market } \\
(1,000,000 \mathrm{KRW})\end{array}$ & 14,114 & 25,524 & 26,548 & 27,249 & 26,946 & 27,276 & 29,425 & 32,179 & 33,977 & 36,285 \\
\hline $\mathrm{CR}_{3}$ & $41.6 \%$ & $45.3 \%$ & $43.2 \%$ & $41.6 \%$ & $40.7 \%$ & $42.0 \%$ & $42.2 \%$ & $42.8 \%$ & $41.3 \%$ & $41.4 \%$ \\
\hline $\mathrm{CR}_{5}$ & $54.2 \%$ & $54.8 \%$ & $52.7 \%$ & $51.0 \%$ & $50.9 \%$ & $52.1 \%$ & $51.9 \%$ & $52.8 \%$ & $52.3 \%$ & $53.0 \%$ \\
\hline $\mathrm{CR}_{10}$ & $73.4 \%$ & $72.2 \%$ & $71.4 \%$ & $71.8 \%$ & $70.8 \%$ & $71.7 \%$ & $71.9 \%$ & $72.8 \%$ & $72.4 \%$ & $72.6 \%$ \\
\hline $\mathrm{CR}_{20}$ & $92.1 \%$ & $91.6 \%$ & $91.3 \%$ & $91.1 \%$ & $91.1 \%$ & $91.3 \%$ & $91.1 \%$ & $91.3 \%$ & $91.5 \%$ & $91.9 \%$ \\
\hline
\end{tabular}

Note: Concentration ratio $\left(\mathrm{CR}_{\mathrm{k}}\right)$ means the proportion of the cost from the highest k products out of the total market cost. As of December 2020 , 67 treatments ( 680 products) are listed as simple formulation, and 56 treatments ( 626 products) are listed as mixed formulation on the National Health Insurance. 
prescriptions (680 items), and CR3, which represents the top three prescriptions, accounted for $93.8 \%$ of the total, showing a high concentration with a significant increase compared to the $22.1 \%$ it accounted for in 2010. During the same period, the concentration of the top five herbal preparations, CR5, increased from $29.7 \%$ to $95.8 \%$, and the concentration of the top 10 herbal preparations, CR10, increased from $44.4 \%$ to $99.2 \%$.

In December 2019, a total of 56 prescriptions (626 items) were listed in the herbal preparation payment list, of which CR3 was $41.4 \%$, showing a lower concentration than that of single herbal preparations. In comparison to the $41.6 \%$ CR3 concentration in 2010, the concentration level was almost unchanged. During the same period, CR5 decreased from $54.2 \%$ to $53.0 \%$, CR10 from $73.6 \%$ to $73.4 \%$, and CR20 from $92.1 \%$ to $91.9 \%$. Additionally, the overall increase in claims for single herbal and mixed herbal preparations was $37.5 \%$ and $11.1 \%$, respectively, and the concentration of certain herbal preparations was also greater in single herbal preparations, which intensified during the analysis period.

\section{DISCUSSION}

This study used statistics for 2010-2019, during the time when the International Classification of Diseases (ICD) code for herbal preparations in the National Health Insurance (NHI) was refined to reconstruct the approximate claims of herbal preparations and suggest the implications of changes in the use of herbal preparations. By looking at these changes over the past decade, we have been able to observe changes in herbal treatment expense, claims of herbal preparations, and the characteristics of these prescriptions and the patients taking them. More importantly, by looking at the change in expense by the prescription name of herbal preparations, frequently used herbal preparations were identified annually, as were the intensified concentrations of use of certain single herbal preparations.

Among the results of the study, the results presented in the annual statistics on herbal preparations are as follows. First, the use of herbal preparations increased more rapidly than Korean medical expenses in NHI. In 2019, Korean medical expenses amounted to about 3 trillion KRW, or 3.8\% of the total health insurance expenses, which have increased by $6.7 \%$ annually over the past decade. On the other hand, herbal preparation was reported to be worth $\# 38.2$ billion KRW in 2019, which accounts for only $1.3 \%$ of Korean medical expenses and $0.05 \%$ of total health insurance costs. Despite this, its annual growth rate was $11.6 \%$ during the same period, which was greater than that of Korean medical expenses. Although small, the dynamic changes in herbal preparation use in the public domain will be an important reference for improving the herbal preparationrelated system and establishing policies.

Second, statistics by age group showed that the use of herbal preparations in women was higher than that in men and has increased rapidly. While herbal preparation use in patients aged 0-19 has decreased, its use in people $\geq 65$ years has increased significantly, suggesting that its use by older patients has led to an increase in the claims of herbal preparations. However, the number of prescriptions for herbal preparations in the elderly has increased by approximately $50 \%$ each year, whereas the prescription expense has increased by $29 \%$, which indicates that the bills per case in this population are gradually decreasing, thereby suggesting more low-unit-cost prescriptions.

Third, regional statistics showed that Seoul had the most herbal preparation use. However, considering that the use of herbal preparations was mainly by the elderly, it was expected that many herbal preparations would be used in areas where the population has aged due to its distribution. Given that the growth rate has increased more rapidly in provincial areas than in Seoul or metropolitan cities, one cannot doubt that there is a link between the aging level by region and herbal preparation prescription.

The analysis of each type of herbal preparation has also produced meaningful results, with the expense of claims made by the top single herbal preparations, such as Paeonia lactiflora and Glycyrrhizae Radix, accounting for a large portion of the total herbal preparations. In 2019, CR3 was 93.8\%, meaning that claims for three single herbal preparations-Paeonia lactiflora, Glycyrrhizae Radix, and Panax ginseng-accounted for $93.8 \%$ of the total 67 prescriptions. This concentration has intensified rapidly over the past decade, whereas other prescriptions have been decreasing, resulting in the total expense of claims for single herbal preparations increasing significantly. Notably, this phenomenon has been observed more severely in single herbal than in mixed herbal preparations. In comparison, the concentration of mixed herbal preparations (CR3, CR5, CR10, and CR20) did not change significantly during the analysis period. However, there has been a rapid increase in some prescriptions, such as Gungghal-tang.

Patterns regarding the prescriptions by KM doctors for these herbal preparations can be interpreted as the result of a system designed to raise the total treatment cost for senior citizens 
from $15,000 \mathrm{KRW}$ to $20,000 \mathrm{KRW}$ when administered by KM institutions. These institutions have a structure in which the total cost of medication is included in the total medical expenses when patients take insurance-covered KM. In this case, if the cost of medication increases, the total medical expenses may exceed the standard for the flat-rate system application in the elderly. In such cases, it will be converted to a fixed-rate system, possibly resulting in a sharp increase in personal burden compared to the flat-rate system. Considering this environment, it can be explained why herbal medicine prescriptions have been increasing in the elderly while the administrative fee per prescription is decreasing. Additionally, considering that the main target of KM clinics is the elderly and women, it can be estimated that herbal preparation use is increasing due to these populations. Furthermore, the high concentration of Paeonia lactiflora and Glycyrrhizae Radix among sweetened herbal preparations can be explained by the omission of Jakyakgamcho-Tang, which is often used for muscle and joint pain.

Based on the 2019 statistics, the expense of claims for single herbal preparations was only 1.9 billion KRW, but that for mixed herbal preparation was 36.3 billion KRW, which shows that $95 \%$ of the prescription expense for herbal preparations was in mixed herbal preparations. This can be seen as a big result of the current medical charge of herbal preparations, which tend to prefer mixed herbal preparations due to the difficultly of preparing prescriptions with various kinds of single herbal preparations in the clinical setting. Therefore, it would be desirable to reasonably revise the medical charge of single herbal preparations or diversify the standard prescription of mixed herbal preparations so that appropriate herbal preparations can be prescribed to patients.

Given that herbal preparation is a prescription that is covered by health insurance benefits and is managed according to the payment list, its prescription and usage are accumulated as big data. This means that more in-depth analyses on herbal preparation use, herbal prescription, and effectiveness are likely to be used through the aggregation of these data from patient groups in the future. This study is the first long-term aggregation of herbal preparation use covered by insurance and is meaningful in providing basic academic and policy data.

However, it should be noted that the situation of herbal preparations excluded from insurance cannot be determined, that various external variables can act on the prescription patterns of herbal preparations, and that sufficient time series data were not analyzed before and after 2011, when the flat-rate scheme for the elderly was introduced.

\section{CONCLUSION}

In this study, the usage status of herbal preparations covered by health insurance was analyzed by reconstructing the drug statistics of the HIRA data for 2010-2019. As a result, it was found that even if the size of herbal preparations was small, the use of herbal preparations has increased more rapidly than the total cost of KM over the past decade, especially among the elderly. However, many of the increased prescriptions were lowcost, which was closely related to the rapid increase in single herbal preparations. Furthermore, these single herbal preparations were concentrated on a small number of herbs, including Paeonia lactiflora, Glycyrrhizae Radix, and Panax ginseng.

Health preparation covered by NHI is an area where claims data have been accumulated following the establishment of health care big data. Moreover, there are various possibilities for future research using this data, as the basic results of this study will be a reference for future research and policy arrangements.

\section{ACKNOWLEDGMENTS}

This research was conducted with the support of the Research Service Project of the Korea Institute of Korean Medicine.

\section{CONFLICTS OF INTEREST}

The authors declare no conflicts of interest.

\section{FUNDING}

The authors received no financial support for the research, authorship, and publication of this article.

\section{ORCID}

Hye-Jae Lee, https://orcid.org/0000-0002-1010-4925

Hye In Jeong, https://orcid.org/0000-0002-3651-9678

Kyeong Han Kim, https://orcid.org/0000-0003-4868-9145

\section{REFERENCES}

1. National Law Information Center. Pharmaceutical Affairs Act 
[Internet]. Sejong: Ministry of Government Legislation; 2021 [cited 2021 Feb 19]. Available from: https://www.law.go.kr/.

2. Health Insurance Review \& Assessment Service. Notice No.2020-338 List of Herbal Medicinal Preparations Covered with National Health Insurance and Upper Limit Amount Table [Internet]. Wonju: Health Insurance Review \& Assessment Service; 2020 [cited $2021 \mathrm{Feb}$ 19]. Available from: https://www.hira. or.kr/rd/insuadtcrtr/bbsView.do?pgmid=HIRAA030069000400 \&brdScnBltNo $=4 \&$ brdBltNo=51741\&isPopupYn=Y.

3. Wonkwang University Industry-Academic Cooperation Group. A Report for the Rational Improvement of the Standard Prescription of Herbal Medicine [Internet]. Wonju: Health Insurance Review \& Assessment Service; 2014 [cited 2021 Aug 6]. Available from: https://policy.kiom.re.kr/sub0401/articles/view/ tableid/sub0301-board/page/20/id/313.

4. Lee I, Park SM, Park SC, Kim DH, Cho MK, Han CW, et al. Overview of the interaction between warfarin and Korean herbal medicine. Korean J Orient Int Med. 2012;33(2):160-71.

5. Kim DH, Lee DE, Noh JW, Ahn YM, Ahn SY, Lee BC. A study of the co-administration of herbal and Western medicines to hospitalized patients with osteoarthritis. J Int Korean Med. 2018; 39(2):97-106.

6. Park HJ, Oh MS, Kim EJ, Lee SG, Park SK, Kim YK. The analy- sis of main diseases and herbal preparations in herbal health insurance. Korea J Herbol. 2006;21(4):1-10.

7. Kang SH, Kim JH, Jang SB, Lee MY, Lee JA, Park SJ. Herbal medicine prescription analyses of bronchiectasis patients with claim data during 5 years (2013 2017). J Soc Prev Korean Med. 2019;23(3):1-12.

8. Kwon YC, Yoo WK, Seo BI. A study on the current status of prescribed drugs in oriental health insurance and their improvement. Korea J Herbol. 2012;27(2):1-16.

9. Kim KH, Lee EK, Go HY, Chang SW, Ju SW, Jang BH, et al. The awareness and satisfaction of herbal medicine preparations of Korean medicine doctor. J Soc Prev Korean Med. 2017;21(2):1522.

10. Health Insurance Review \& Assessment Service. National Health Insurance Drug Statistics 2019 [Internet]. Wonju: Health Insurance Review \& Assessment Service; 2020 [cited 2021 Feb 19]. Available from: http://www.hira.or.kr/bbsDummy.do?pgmid=H IRAA020045010000\&brdScnBltNo=4\&brdBltNo=2331\&pageIn $\operatorname{dex}=1$.

11. Heo J. Reimbursement price, market structure, and pharmaceutical firm behavior in Korea [dissertation]. [Seoul]: Seoul National University; 2011. 187 p. 